\title{
Analysis of the Energy Potential of Renewable Energy Sources Egypt
}

\author{
S. Obukhov ${ }^{1}$, and $A$. Ibrahim ${ }^{1, *}$ \\ ${ }^{1}$ National Research Tomsk Polytechnic University, 634050 Tomsk, Russia
}

\begin{abstract}
The article reviews the current energy balance of Egypt's resources and sources of consumption, the main factors affecting the structure of the energy balance, the predicted trends of their changes in the short term, the main tasks of the electric power industry of Egypt and the ways of their solution. Based on the analysis of energy potential of renewable energy sources, the proposed types and locations of installations of renewable energy those have the greatest prospects for practical application.
\end{abstract}

\section{Introduction}

Egypt is a country in Northeast Africa; From the north, it is washed by the Mediterranean, and from the east by the Red Sea. The area of the country is 1001 thousand $\mathrm{km}^{2}$. The population of Egypt in 2016 amounted to 90 million people and grows by $1.3 \%$ per year. The average population density is about 70 people per $\mathrm{km}^{2}$, of which $57 \%$ live in villages and $43 \%$ live in cities [1]. The country is rich in natural resources, among which there are various minerals: precious stones, natural gas, oil, coal and arable land. From the point of view of the energy balance, Egypt has large reserves of fossil energy sources. On the mainland and coastal deposits, oil reserves are 4189 billion barrels, gas reserves are estimated at 77,200 billion $\mathrm{m}^{3}$.

Currently, about $90 \%$ of electricity in Egypt is produced with the use of fossil fuels and mainly of power plants operating on gas. The rapidly growing demand for electricity caused by demographic factors and the widespread use of low-efficiency electrical appliances has exceeded the level of domestic gas production, as well as the capacity of power systems and the generation of electricity, which leads to the regular formation of power shortages and fan outages. This leads to a depletion of fiscal resources of the state, creates a threat to the functioning of the economy of Egypt in the absence of reliable power supply of population and industry of the country. The data in Fig. 1 gives an idea of the annual growth in peak load of the country, which increased on average by $6 \%$ per year [2].

\footnotetext{
Corresponding author: ibragim@tpu.ru
} 


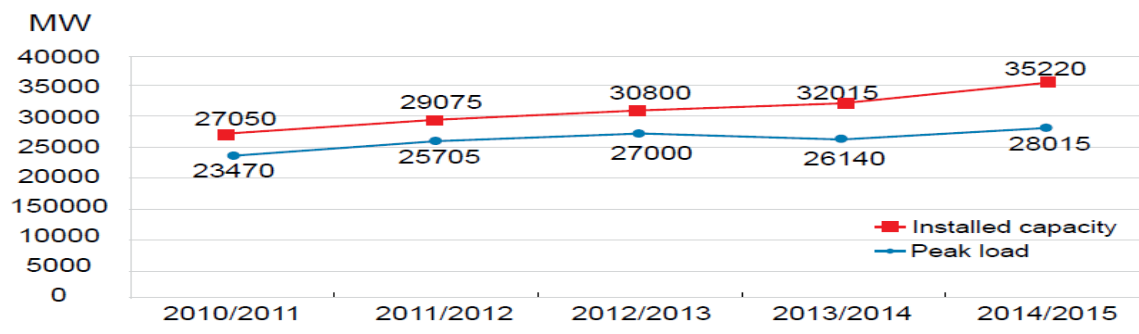

Fig.1. Dynamics of growth of peak load power system in Egypt.

The main objectives of the power sector in Egypt at the present stage are the creation of new generating power capacity and electrification of remote rural areas. In addressing these objectives, it is necessary to take into account, on the one hand, the tightening of requirements for environmental protection, the country's economic possibilities, the difficulties, and due to the limited reserves of fossil fuels, and on the other hand the availability of significant renewable energy sources $[2,3]$.

\section{Research Methods and results}

The analysis of energy potential of renewable energy sources shows that Egypt is rich in resources of solar energy, and in the Gulf of Suez includes some of the world's richest resources of wind energy. The development of these abundant renewable energy resources can contribute to increasing power generating capacity and reduce the country's dependence on natural gas imports. Wind and solar Atlas of Egypt (Fig. 2) shows the potential use of renewable energy sources (RES) for generating electricity. The areas along the coast of the Mediterranean Sea in northern Egypt are the most suitable for the use of wind and solar energy. It should be noted that in this place there are new rural areas that are not connected to a centralized network [1].

The increase in the consumption of electricity in Egypt is 6-7\% per year [3], and in order to provide the necessary funds, the government is considering plans for the partial privatization of the electricity industry, increasing foreign investment. The total installed capacity of power plants amounted in 2010 to 27.05 GW (Fig.1) by the year 2015 increased to $35.2 \mathrm{GW}[1,2,3]$. The installed capacity of thermal power plants based on natural gas is $52 \%$, and only $1,4 \%$ is accounted for by power plants based on wind energy.
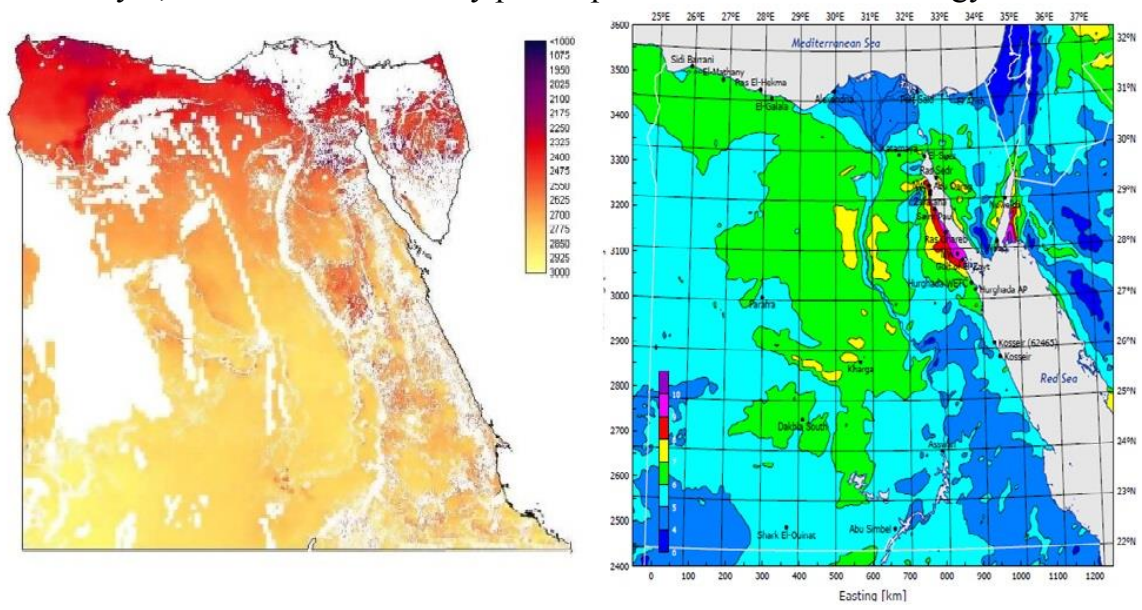

Fig.2. Wind atlas and solar atlas of Egypt. 
At present, Egypt provides electricity to $99 \%$ of its population. Egypt's need for energy in the period from 1997 to 2008 has grown by an average of $7 \%$ per year and will increase in the range of $15-25 \%$ per year for the next twenty years. The Egyptian government hopes that by $2020,20 \%$ of the installed capacity in the country will use renewable energy sources $[1,4]$.

Agriculture on new lands in the desert is getting great development. The country sent about 1.26 million hectares for the development of new lands in the desert. Approximately half of this land is located outside the centralized power supply zones. In order to provide power supply to these farms, it is necessary to use autonomous power supply system's [4]. The Main Energy Council in Egypt decided to expand the use of renewable energy sources in order to achieve $20 \%$ of the total electricity production in 2020 (hydroelectric power plants $8 \%$ and wind power plants $12 \%$ ) [5].

This can be achieved through the participation of private capital in the creation of wind farms in Egypt. According to annual data from renewable energy sources, the number of hours of sunshine per year in the north of Egypt is $3400 \mathrm{~h}$ and $3900 \mathrm{~h}$ in the south, and the average annual solar radiation in the north is $1900 \mathrm{kWh} / \mathrm{m}^{2}$ and in the south $2600 \mathrm{kWh} /$ $\mathrm{m}^{2}$ (Fig.3). Consequently, almost the entire territory of the country the amount of solar radiation is large enough and almost year-round operation of solar power plants. Currently, the total installed solar capacity in Egypt is 145,2 MW, including the capacity of thermal power stations in Kureimat, located $92 \mathrm{~km}$ South of Cairo [2], by 2020 it is planned to increase to $2.13 \mathrm{GW}$ with power generation of $7.35 \mathrm{GW} \cdot \mathrm{h}$ [7].

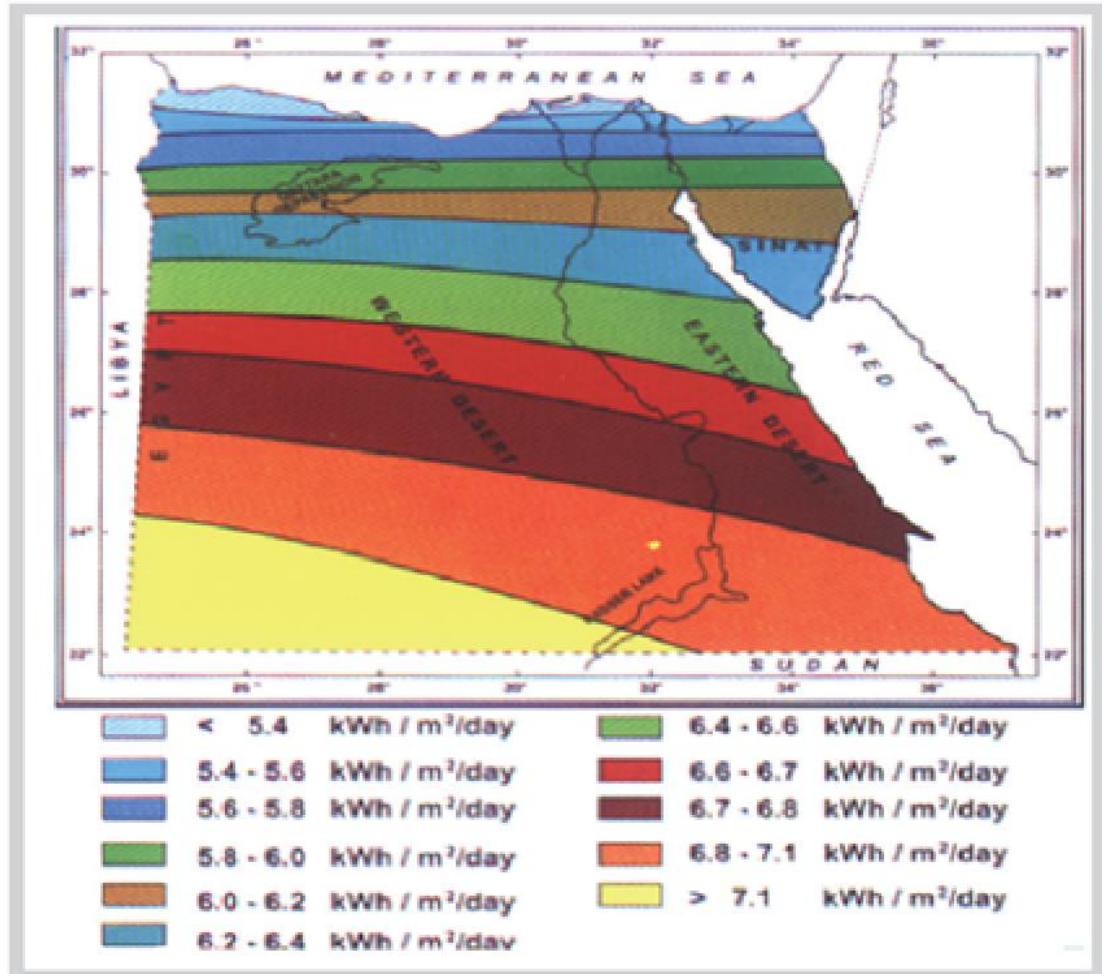

Fig.3. The distribution of solar radiation on the territory of Egypt.

The West of the Gulf of Suez is the most promising place for the construction of large wind power stations due to the wind speed, which varies between $8-10 \mathrm{~m} / \mathrm{s}$, and also due to the low population density in this area (fig2). There are other promising places with a wind speed of 7-8 m/s in the east and west of the Nile River near the cities of Beni Suaiwa 
and Minia. At present, there are two wind farms in Egypt Hurghada and Zafarana wind farms (fig 4) installed wind power plants in Zafaran, their generation of electricity in $2012 / 2013$.

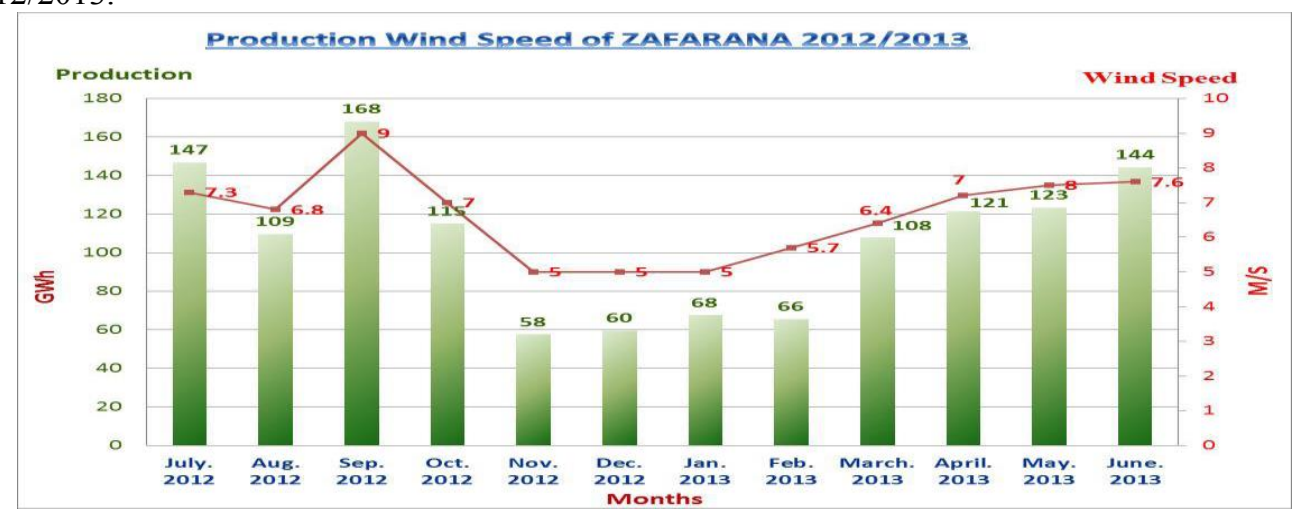

Fig.4. Production of electricity of Zafarana 2012/2013.

\section{Conclusion}

The increase in electricity generation in Egypt can be ensured by the use of local energy resources, including renewable energy sources. The level of solar radiation in Egypt is high enough that it allows expanding the share of solar power stations in the energy sector of the country. A high average annual wind speed in the east and north of the country, reaching 8$10 \mathrm{~m} / \mathrm{s}$, allows using economical wind power plants.

The work was carried out within the framework of the implementation of the Federal Target Program "Research and Development in Priority Areas for the Development of the Russian Science and Technology Complex for "2014-2020", a unique project identifier No. 14.576.21.0098.

\section{References}

1. Arab Republic of Egypt, Ministry of Electricity and Energy, Annual Report

2. Arab Republic of Egypt Central Agency for Public Mobilization and Statistics www.msrintranet.capmas.gov.eg.

3. REN21 Renewable Energy Policy Network for the 2E 'Century, (2011)

4. Wind atlas for Egypt. Research and development department, the Egyptian Meteorological Authority, Cairo, Egypt in (2006)

5. Energy in Egypt. Year Book of Egypt. Egypt State Information Service, Cairo (2008)

6. Energy Information Administration (EIA). Egypt Energy Data, Statistics and Analysis Oil, Gas, Electricity, Coal.http://tonto.eia.doe.gov/cfapps/ipdbproject/EEDIndex3.cfm?tid=5\&pid=:53\&aid.

7. Arab Republic of Egypt. Central Agency for Public Mobilization and Statistics. Annual report (2007/2008) 